\title{
Successful Surgical Treatment of a Spontaneous Rupture of the Esophagus Diagnosed Two Days after Onset
}

\author{
Hiroyuki Ando ${ }^{a, b}$ Yoshinori Shitara $^{a, b}$ Kei Hagiwara ${ }^{a}$ \\ Keigo Hara ${ }^{a, b}$ Yasushi Mogami ${ }^{a, b}$ Tsutomu Kobayashi ${ }^{a, b}$ \\ Toshiki Yajima $^{a, b}$ Masachika Tani ${ }^{a, b}$ Nobuhiro Morinaga ${ }^{a, b}$ \\ Masatoshi Ishizaki $i^{a}$ Hiroyuki Kuwano $^{\text {b }}$ \\ ${ }^{a}$ Department of Surgery, Fujioka General Hospital, Fujioka, and ${ }^{b}$ Department of \\ General Surgical Science, Graduate School of Medicine, Gunma University, \\ Maebashi, Japan
}

\section{Key Words}

Spontaneous rupture $\cdot$ Esophagus

\begin{abstract}
Esophageal perforation is a relatively uncommon disease with a high rate of mortality and morbidity. Delay in the diagnosis and treatment occurs in more than $50 \%$ of cases, leading to a mortality rate of $40-60 \%$. Primary repair is generally considered the gold standard for patients who present within the first $24 \mathrm{~h}$ following perforation of the esophagus. In this paper, we present a case of successful surgical treatment of spontaneous rupture of the esophagus that was diagnosed 2 days after onset. The patient was a 42-year-old man admitted to internal medicine with a diagnosis of pleuritis and complaining of chest and back pain. The next day, computed tomography revealed left-sided pleural effusion and mediastinal emphysema. An esophagogram revealed extravasation of the contrast medium from the lower left esophagus to the mediastinal cavity. These results confirmed a rupture of the esophagus, and an emergency left thoracotomy was performed. The perforation was repaired with a single-layered closure and was covered with elevated great omentum obtained by laparotomy. The patient was discharged 23 days after the first surgery. In conclusion, primary repair surgery must be selected as the best treatment beyond $24 \mathrm{~h}$ if the patient's general state was stable and there was no evidence of clinical sepsis.
\end{abstract}




\section{Introduction}

Esophageal perforation is a relatively uncommon disease with a high rate of mortality and morbidity [1]. The etiology of esophageal perforations is commonly of two types: iatrogenic and spontaneous perforation (Boerhaave's syndrome). Other less common causes include perforations secondary to malignancy or trauma. Perforations of any cause are uncommon, making early diagnosis difficult, particularly in spontaneous perforations, which mimic more common serious intrathoracic conditions such as myocardial infarction. However, the importance of early diagnosis and prompt surgical treatment of a perforated esophagus cannot be overstated. Considering the rarity of this condition and its nonspecific presentations, delay in diagnosis and treatment occurs in more than $50 \%$ of cases [2]. The mortality rate rises from 40 to $60 \%$ if diagnosis and initiation of optimal treatment are delayed, but this rate decreases to $10-25 \%$ if treatment is carried out within $24 \mathrm{~h}$ of perforation [2]. However, in this paper we present a case in whom a spontaneous esophageal perforation was successfully treated by emergency surgery more than $24 \mathrm{~h}$ after the onset was reported.

\section{Case Report}

A 42-year-old man visited a nearby hospital with severe chest and back pain after vomiting. Electrocardiography findings were not typical of acute myocardial infarction. Computed tomography (CT) showed slight left pleural effusion. The patient was admitted to our hospital with a diagnosis of pleuritis. The next day, the pain gradually worsened. CT was reexamined, revealing a large amount of pleural effusion on the left side and mediastinal emphysema (fig. 1). An esophagogram revealed extravasation of the contrast medium (Gastrografin) from the lower left esophagus to the mediastinal cavity (fig. 2 ). These results confirmed a rupture of the esophagus, and an emergency left thoracotomy was performed $31 \mathrm{~h}$ after the onset of symptoms. A 5-cm perforation was discovered in the left lateral wall of the lower esophagus (fig. 3a). The perforation was repaired with a single-layered closure (fig. $3 \mathrm{~b}$ ) and covered with elevated great omentum obtained by laparotomy (fig. 3c). In the 7 days after the surgery, laboratory examinations showed the following abnormalities: white blood cells 20,640 and C-reactive protein 11.4. An esophagogram revealed no extravasation. CT showed a residual abscess, or empyema, on the left side. Treatment involved drainage by video-assisted thoracic surgery, and oral intake was started the next day. The patient was discharged 23 days after the first surgery.

\section{Discussion}

Spontaneous esophageal rupture, while uncommon, is associated with significant mortality. Reported mortality rates range from 8 to $60 \%$ [3]. The condition is often confused with many other disorders, such as myocardial infarction, peptic ulcer, pancreatitis, dissecting aortic aneurysm and pulmonary embolism, because the disease is extremely rare and the classic findings of vomiting, chest pain and subcutaneous emphysema are often absent in early cases [4]. Therefore, in the present case, cardiovascular disease, including acute myocardial infarction, was initially suspected. However, the next day, a chest CT revealed pleural effusion and mediastinal emphysema, and spontaneous esophageal rupture was correctly diagnosed without any critical delay. 
Spontaneous esophageal rupture is believed to occur through the transmission of increased intra-abdominal pressure to the esophagus against the closed glottis. In many instances, it is associated with violent retching and vomiting, which cause a sudden increase in intraesophageal pressure [5]. Most cases follow bouts of heavy eating and drinking [3]. In the present case, an episode of heavy vomiting was mentioned. Accordingly, the clinical course was thought to be typical for spontaneous esophageal rupture.

Successful management depends on early diagnosis and prompt treatment, as the morbidity and mortality rates rise rapidly after the first 12-24 $\mathrm{h}$ [6]. Brinster et al. [7] have reported that delays in treatment of more than $24 \mathrm{~h}$ after perforation can result in a doubling of the mortality rate from $14 \%$ if diagnosed early to $27 \%$ if diagnosed late. However, due to relative rarity and nonspecific presentations of the disease, delay in diagnosis and treatment occurs in more than $50 \%$ of esophageal perforations [8]. Treatment of esophageal perforation, especially ruptures that are diagnosed late or missed, remains a challenge, with controversy surrounding its optimal management [8].

Treatment options include nonoperative and operative procedures. Nonoperative management of esophageal perforation has been advocated in selected situations. Conservative therapy should not be used in patients with free intrapleural perforation. Cameron proposed three criteria for nonoperative management: first, the perforation must be contained in the mediastinum and should be drained back into the esophagus; second, there should be mild symptoms; and third, there should be minimal evidence of clinical sepsis [9]. Our patient's condition did not match these criteria.

Operative strategies can be further subdivided into primary repair with or without reinforcement, simple drainage of the thoracic cavity, an exclusive diversion operation, occlusion of the perforation site with a prosthesis, and esophageal resection with or without reconstruction [7]. The choice of operative strategy depends on the cause, location of the injury, underlying esophageal diseases, time interval after the perforation, extension of spillage, edge of wound, age and presence of any comorbidity [1].

Although many believe that primary repair is the gold standard for patients who present within the first $24 \mathrm{~h}$ following perforation [9], primary repair can be done regardless of the time interval between perforation and treatment if esophageal tissue is repairable and the wound edges are viable after necrosectomy, there is no distal obstruction, and the size of the defect is not greater than one-third the circumference of the esophagus [10]. On the other hand, postoperative leakage has been reported to occur in $83 \%$ of cases treated more than $24 \mathrm{~h}$ after onset [11]. In the present case, we could select primary closure more than $24 \mathrm{~h}$ after onset because the patient was young, his general state was stable, there was no evidence of clinical sepsis, the esophageal tissue was repairable, and the wound edges were viable without necrosis. And more importantly, we could select patching with elevated great omentum as the repair method regardless of various surgical techniques to reinforce primary closure with either tissue or mesh or pericardial fat $[12,13]$ because great omentum is rich in blood flow and resists wound infection. An esophagogram revealed no extravasation and there was no postoperative leakage. Our case suggests the importance of surgical treatment, even in patients more than $24 \mathrm{~h}$ after the onset of symptoms. 


\begin{tabular}{r|l|l|l}
$\begin{array}{r}\text { Case Reports in } \\
\text { Gastroenterology }\end{array}$ & $\begin{array}{l}\text { Case Rep Gastroenterol 2012;6:260-265 } \\
\text { DOI: 10.1159/000338653 }\end{array}$ & $\begin{array}{l}\text { Published online: } \\
\text { May 8, 2012 }\end{array}$ & $\begin{array}{l}\text { @ 2012 S. Karger AG, Basel } \\
\text { ISSN 1662-0631 } \\
\text { www.karger.com/crg }\end{array}$ \\
\hline
\end{tabular}

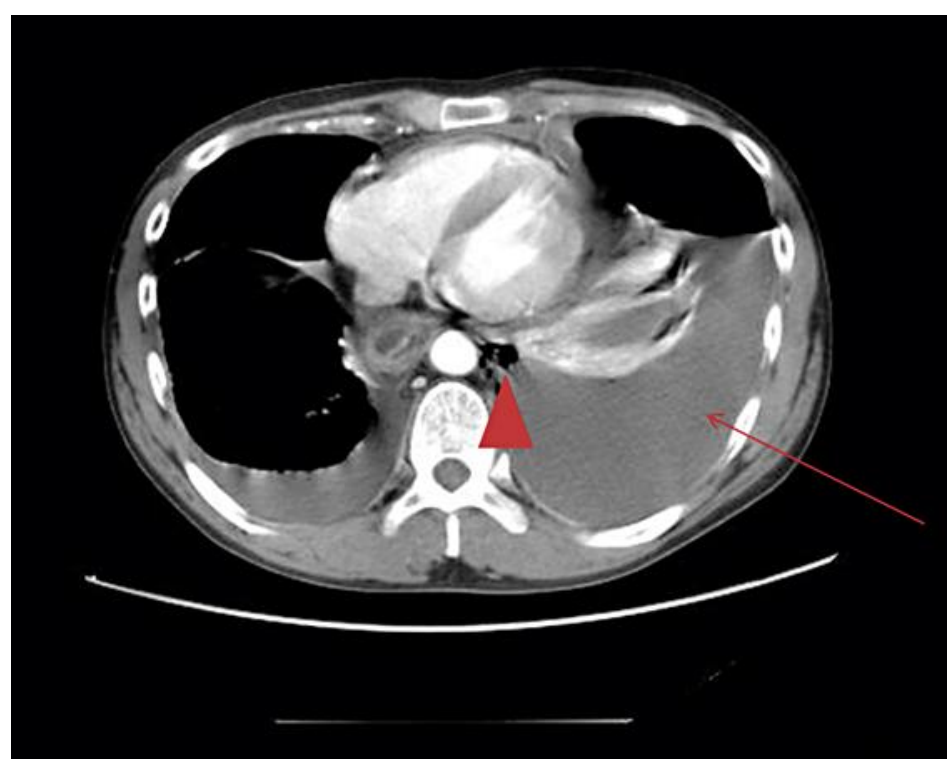

Fig. 1. A CT image showed a large amount of pleural effusion on the left side (arrowhead) and mediastinal emphysema (arrow).

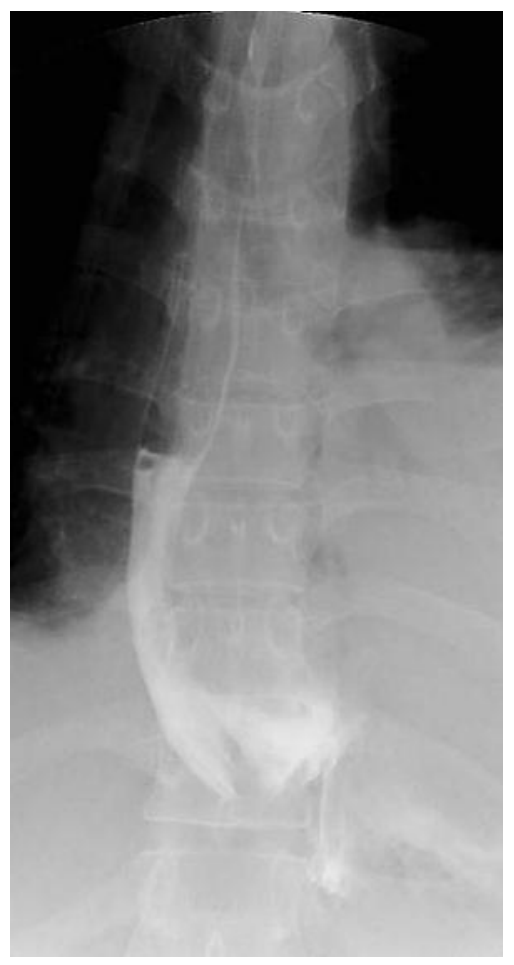

Fig. 2. An esophagogram revealed extravasation of contrast medium (Gastrografin) from the lower left esophagus to the mediastinal cavity. 


\begin{tabular}{r|l|l|l} 
Case Reports in & $\begin{array}{l}\text { Case Rep Gastroenterol 2012;6:260-265 } \\
\text { DOI: 10.1159/000338653 }\end{array}$ & $\begin{array}{l}\text { Published online: } \\
\text { May 8, 2012 }\end{array}$ & $\begin{array}{l}\text { @ 2012 S. Karger AG, Basel } \\
\text { ISSN 1662-0631 } \\
\text { www.karger.com/crg }\end{array}$ \\
\hline
\end{tabular}
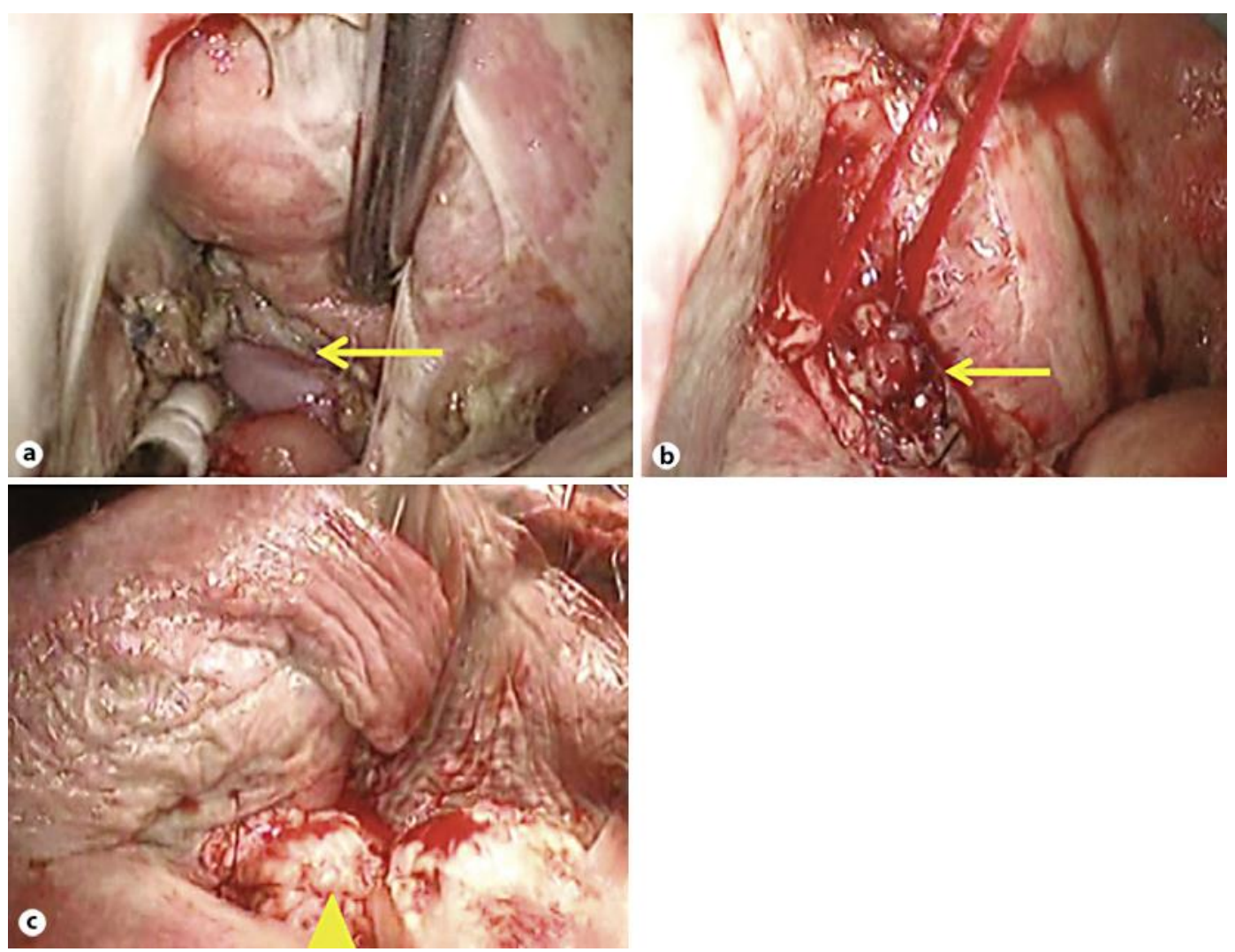

Fig. 3. a A 5-cm perforation was discovered in the left lateral wall of the lower esophagus (arrow). b The perforation was repaired with a single-layered closure (arrow). c The perforation was covered with elevated great omentum obtained by laparotomy (arrowhead).

\section{References}

1 Sng KK, Koh AJH, Tan NC, Tan SM, Tay KH: An eastern perspective on oesophageal perforation: a high incidence of ingested bones. ANZ J Surg 2008;78:573-578.

-2 Bladergroen MR, Lowe JE, Postlethwait RW: Diagnosis and recommended management of esophageal perforation and rupture. Ann Thorac Surg 1986;42:235-239.

-3 Keighley MRB, Girdwood RW, Ionescu MI, Wooler GH: Spontaneous rupture of the oesophagus. Br J Surg 1972;59:649-652.

-4 Ojima H, Kuwano H, Sasaki S, Fujisawa T, Ishibashi Y: Successful late management of spontaneous esophageal rupture using T-tube mediastinoabdominal drainage. Am J Surg 2001;182:192-196.

5 Singh GS, Slovis CM: Occult Boerhaave's syndrome. J Emerg Med 1988;6:13-16.

6 Mason GR: Esophageal perforations, anastomotic leaks, and strictures: the role of prostheses. Am J Surg 2001;181:195-197.

-7 Brinster CJ, Singhal S, Lee L, et al: Evolving options in the management of esophageal perforation. Ann Thorac Surg 2004;77:1475-1483.

8 Gupta NM, Kaman L: Personal management of 57 consecutive patients with esophageal perforation. Am J Surg 2004;187:58-63.

-9 Skinner DB, Little AG, DeMeester TR: Management of esophageal perforation. Am J Surg 1980;139: 760-764.

10 Kiss J: Surgical treatment of oesophageal perforation. Br J Surg 2008;95:805-806. 
11 Wang N, Razzouk AJ, Safavi A, et al: Delayed primary repair of intrathoracic esophageal perforation: is it safe? J Thorac Cardiovasc Surg 1996;111:114-122.

12 Bardaxoglou E, Campion JP, Landen S, et al: Oesophageal perforation: primary suture repair reinforced with absorbable mesh and fibrin glue. Br J Surg 1994;81:399.

13 Bufkin BL, Miller JI, Mansour KA: Esophageal perforation: emphasis on management. Ann Thorac Surg 1996;61:1447-1452. 